\title{
Estimation of the Inland Transport Performance from the Consolidated European Road Freight Transport Data
}

\author{
Thomas Karner, Brigitte Weninger, Sylvia Scharl \\ Statistics Austria, Vienna
}

\begin{abstract}
Transportation volumes and performances are commonly used to compare the various transportation modes in certain territories. In Austria, this information is available for vehicles registered in Austria based on the national survey. Data about vehicles registered in other European countries is included in the consolidated European road freight transport statistics that Eurostat provides to the national statistical institutes. These consolidated statistics do not contain information about transport performance in individual EU-member states. This article presents a method for estimating the transport performance of non-Austrian European vehicles operating in Austria. Comparing the results of this approach with those of the Austrian road freight transport survey shows that the model works quite well. Thus, solid estimations of inland transport performance of all European road freight vehicles on Austrian territory are available for the first time.
\end{abstract}

Keywords: transport performance, road freight transport statistics, consolidated European transport statistics.

\section{Introduction}

Transport statistics provide information about transport volume (tonnes transported) and transport performance (tonnes transported multiplied by the distance in kilometres) on defined territories (e.g. for the European Union as a whole or for the individual member states) of the different modes of transport (road, rail, aviation, inland waterways and pipelines).

Unfortunately, the transport performance of the European road freight transport statistics is not available for national territories of single EU-member states. To measure the inland transport performance of foreign road freight vehicles in Austria, an estimation model described in this article was developed.

Two different approaches were taken with respect to the individual transport types. For national transport, international receipt and dispatch the total transport performance (tonnes transported multiplied by the total distance travelled on Austrian and foreign territory) was available and therefore used as the basis for the estimation. For these types of transport, the basic concept of this model was to divide the total distance of each journey into segments - 
one driven on Austrian territory and the other on foreign territory. Thus, the total transport performance was divided into inland and foreign transport components.

For transit transport only, the transport volume (tonnes transported) was given. To estimate the inland transport performance for each journey, the distance in kilometres travelled within Austria had to be determined and then multiplied by the transport volume.

For both estimation processes, the points of loading and unloading of each journey were entered into a digital route planner to obtain the distances travelled on both Austrian and foreign territory. Previously, suitable geo-coordinates for these points had to be defined.

This article includes a description of the data and the programmes used. It also presents a detailed overview of the approach used to estimate the inland transport performance of foreign road freight vehicles. To assess the quality of these calculations, the same estimation was also done for Austrian road freight vehicles and the results were then compared to the actual inland tonne-kilometres, which are available at Statistics Austria.

\section{Data and Methods}

Statistics Austria surveys road freight transport conducted by Austrian road freight vehicles. This sampling survey includes lorries with a loading capacity of 2 tonnes or more and all articulated vehicles, including transport for hire or reward and on own account. For this population, the data collected includes, among others the transport volume, the points of loading and unloading and the border-crossings of each journey on public streets from which the inland and foreign transport performance are calculated (Ordinance on rail and road transport statistics, Federal Law Gazette No 393/1995 as amended by Federal Law Gazette No $119 / 2005^{1}$ ). However, to depict the entire transport performance in Austria, additional information is needed about the inland transport performance of foreign vehicles.

Complying with Regulations (EC) No 70/2012, 202/2010 and 6/2003, each EU member state as well as Norway, Liechtenstein and Switzerland conducts a road freight transport survey based on the same European legal basis. Therefore, each national survey includes the total transport volume carried by road freight vehicles registered in their respective country. Each country transmits this data to the European statistical institute (Eurostat), which then compiles the consolidated European road freight transport statistics. Eight datasets with aggregated data on transport volume and total transport performance in Europe - the so-called "D-tables" - are created. These datasets are provided to the national statistical institutes to complete their national data with the data of the European foreign vehicles.

Concerning transport performance, the D-tables contain only information on the entire route. For this reason it is not possible to gather information on the inland transport performance (in inland tonne-kilometres) from the D-tables for each member state separately. Consequently Statistics Austria developed a procedure to estimate the inland transport performance on Austrian territory from the data existing in two D-tables, D3.1 and D5.

D-table D3.1 includes information on transport operations at the regional level for laden journeys. This table is aggregated on the dimensions of the reporting country, region of loading and unloading, axle configuration, type of cargo and age class of the vehicle and provides information on the transport volume, total transport performance, vehicle kilometres, movements and number of vehicle records. From this table, the road freight transport data for national transport and international receipt and dispatch in Austria can be completed.

D-table D5 holds data on transit transport concerning laden and empty journeys. The aggregated dimensions provided are the transit country, reporting country, laden/empty journey and region of origin and destination. The table contains information on transport volume

\footnotetext{
${ }^{1}$ BGBl. Nr. 393/1995 Verordnung des Bundesministers für öffentliche Wirtschaft und Verkehr über statistische Erhebungen im Bereich des Straßen- und Schienengüterverkehrs (Straßen- und Schienengüterverkehrsstatistik-Verordnung) idF: BGBl. II Nr. 119/2005
} 
in tonnes, movements and the number of vehicle records; the transport performance is not included.

The general concept of the estimation method described in this article is to use the information on the points of loading and unloading of foreign vehicles provided in these D-tables to calculate the distance driven within Austria using the digital route planner Microsoft MapPoint 2011. In combination with the information on tonnes transported and total transport performance, it was hypothesised that an accurate estimation of the inland transport performance of foreign road freight vehicles could be created. To assess the quality of these calculations, a comparison was made between the inland tonne-kilometres driven by Austrian road freight vehicles based on the national survey and on the D-tables.

The points of loading and unloading given in the D-tables were therefore a crucial component. They are classified by the "Nomenclature des unités territoriales statistiques" (NUTS) and are included in the D-tables on NUTS 3 level. Generally the NUTS is a system of hierarchically organised territorial units for statistical purposes established by Eurostat in collaboration with the member states. It divides the territory of the European Union into three levels of territorial areas, which usually consist of entire administrative units: NUTS 1 Regions of the European Communities, NUTS 2 Basic administrative units, NUTS 3 Subdivisions of the basic administrative units (Regulation (EC) No 1059/2003, Commission Regulation (EU) No 1319/2013).

To identify the Austrian route segment, it was necessary to define a representative geocoordinate for each one of the 1,294 NUTS 3 regions, because the NUTS 3 regions are large areas consisting of many zip-codes and communities. These coordinates then served as the points of loading or unloading in Microsoft MapPoint 2011. A representative coordinate was deemed appropriate if the population density of the area was the highest within that NUTS 3 region - in the middle of the biggest city of the region, for example.

To choose the representative coordinates of the NUTS 3 regions, the programme Esri ArcGIS was used. Within this programme, the borders of the countries and the NUTS 3 regions can be displayed in maps. Two digital maps were then selected in which the population density was represented: the Urban clusters 2006 of the European Commission ${ }^{2}$ and the CORINE (Coordination of Information on the Environment) land cover of the European Environment Agency $^{3}$. The maps were loaded into ArcGIS and the borders were superimposed. Furthermore, standard-coordinates from the European Commission (Eurostat GISCO) ${ }^{4}$ for the NUTS 3 regions were included.

The Urban clusters 2006 provide a strongly aggregated view of the landscape concerning population. Only areas with at least 300 inhabitants per $\mathrm{km}^{2}$ are displayed as clusters; otherwise the landscape stays white. The colour of the clusters varies from yellow (low population density) to red (high population density).

For some regions, the Urban clusters 2006 did not provide enough information to make a decision on which coordinate is best suited. This can happen if two or more cities with approximately the same expanse and population are situated within one NUTS 3 region. In those cases, the CORINE land cover was used where different types of land use could be discerned. As shown in Figure 1 CORINE displays for example urban areas and streets (red), industrial compounds (pink, purple), agricultural areas (yellow, orange), forests (green), water bodies (light blue), coastal lagoons (turquoise), wetlands (dark blue) and open spaces with little or no vegetation (grey, black and mint green). With this additional information, suitable representative coordinates could be ascertained.

When the standard-coordinates Eurostat GISCO provides for the NUTS 3 regions were

\footnotetext{
${ }^{2}$ http://epp.eurostat.ec.europa.eu/portal/page/portal/gisco_Geographical_information_maps/ geodata/reference

${ }^{3}$ http://sdi.eea.europa.eu/catalogue/srv/eng/search?uuid=9c50e16b-a1e3-464f-8394-ecb3a709601d

${ }^{4}$ http://epp.eurostat.ec.europa.eu/portal/page/portal/gisco_Geographical_information_maps/ popups/references/administrative_units_statistical_units_1
} 


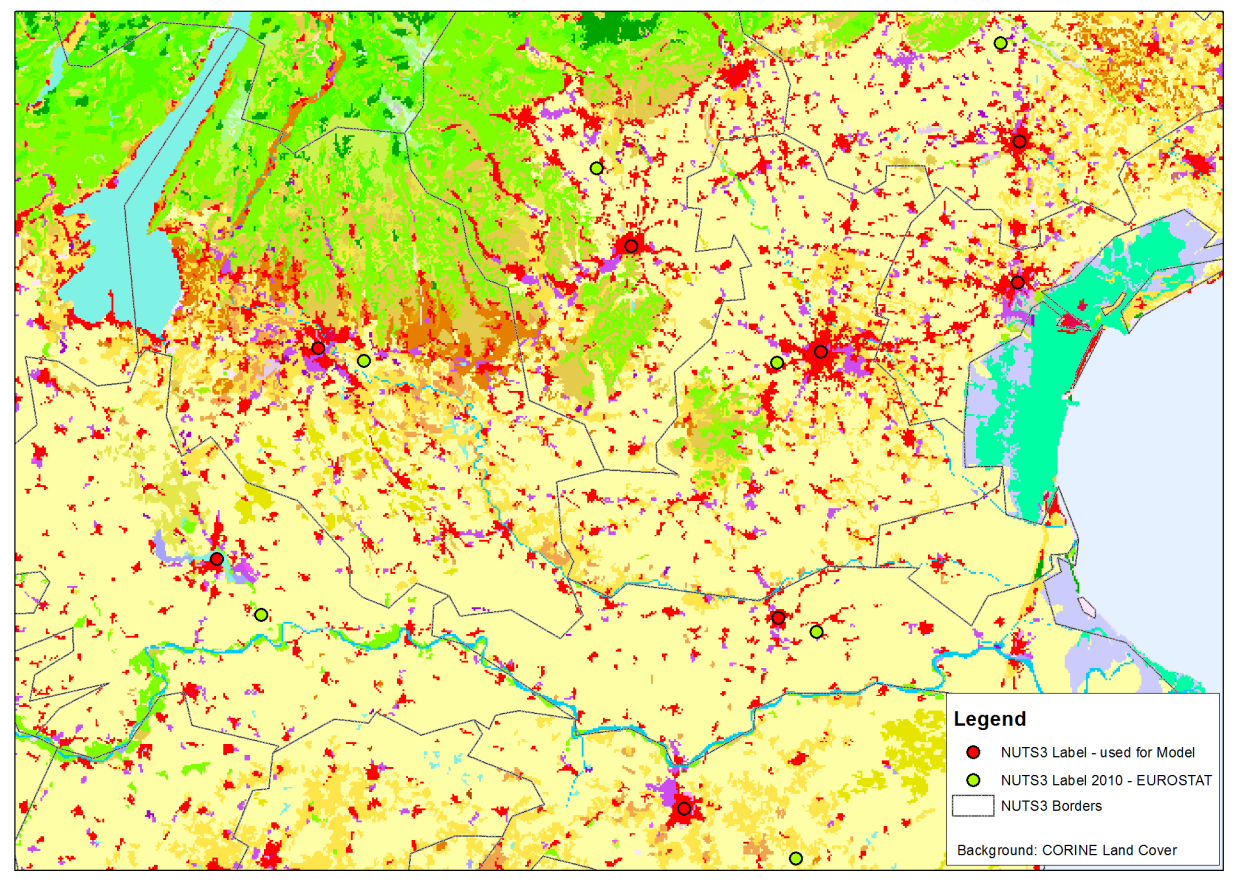

Figure 1: Corine land cover for the province Veneto - including from left to right Lake Garda, Verona, Vicenza, Padua and Venice.

matched to the population density in the digital maps, it turned out that they could not be used for the requested purpose because they often were situated in sparsely populated forests or agricultural areas. For that reason, the aforementioned maps were employed to define more suitable coordinates.

Information on NUTS 3 level was not always available in the D-tables. Some countries (e.g. Russia) are not divided into NUTS regions. Additionally, the digital maps used did not include all countries where trips were recorded to start or end. Therefore, for those countries a coordinate in the middle of their capital was set as the representative coordinate. As those countries tend to be far from Austria, the percentage of the inland kilometres would differ only very slightly if another city in that country would have been selected. Hence the capital was used as an approximation where no detailed information was at hand.

\section{Estimation approach}

Based on the D-Tables from Eurostat, for the several types of transport different estimation approaches were chosen. Hence this section is divided into three subsections: national transport, international receipt/dispatch and transit transport. A fourth part is dedicated to cases where the regional data were incomplete.

The fastest route was used as selection criterion for the route planner in all three estimation approaches. By using the fastest route instead of the shortest, the route chose the main road network whenever possible, as is assumed that road freight vehicles usually do.

\subsection{National Transport}

The definition of national transport (journeys start and end within Austria) would theoretically imply that the entire transport performance was conducted in Austria. However, routes from western to eastern Austria and vice versa usually run partially through Germany the so-called "Deutsches Eck". Thus, the trip segments that ran through Germany had to be subtracted.

As a first step, those routes most likely running through the "Deutsches Eck" had to be 
identified. For this, three zones within Austria were defined: the eastern, the western and the central zone, as displayed in Figure 2. The western zone includes the NUTS 3 regions Außerfern (AT331), Innsbruck (AT332), Tiroler Oberland (AT334), Tiroler Unterland (AT335), Bludenz-Bregenzer Wald (AT341), Rheintal-Bodenseegebiet (AT342), the central zone Klagenfurt-Villach (AT211), Oberkärnten (AT212), Unterkärnten (AT213), PinzgauPongau (AT322), Osttirol (AT333) and the eastern zone all the others: Mittelburgenland (AT111), Nordburgenland (AT112), Südburgenland (AT113), Mostviertel-Eisenwurzen (AT121), Niederösterreich-Süd (AT122), Sankt Pölten (AT123), Waldviertel (AT124), Weinviertel (AT125), Wiener Umland/Nordteil (AT126), Wiener Umland/Südteil (AT127), Wien (AT130), Graz (AT221), Liezen (AT222), Östliche Obersteiermark (AT223), Oststeiermark (AT224), West- und Südsteiermark (AT225), Westliche Obersteiermark (AT226), Innviertel (AT311), Linz-Wels (AT312), Mühlviertel (AT313), Steyr-Kirchdorf (AT314), Traunviertel (AT315), Lungau (AT321), Salzburg und Umgebung (AT323).

For all trips starting and ending within the same zone as well as trips leading to or from the central zone, the inland percentage of the total tonne-kilometres was set to $100 \%$, since they occurred entirely on Austrian territory.

All trips running from the eastern to the western zone or vice versa had to be divided into kilometres driven on Austrian and on German territory. This was done by finding the fastest route between two NUTS 3 regions using Microsoft MapPoint 2011 and registering the suggested border crossings for the eastern zone Walserberg, Suben and Braunau/Inn and for the western zones Hörbranz, Vils and Kiefersfelden. Then the distances between the representative coordinates of the two NUTS 3 regions to the respective border crossings were calculated and summed up. For the nine pairs of border crossings the distances were calculated as the foreign kilometres.

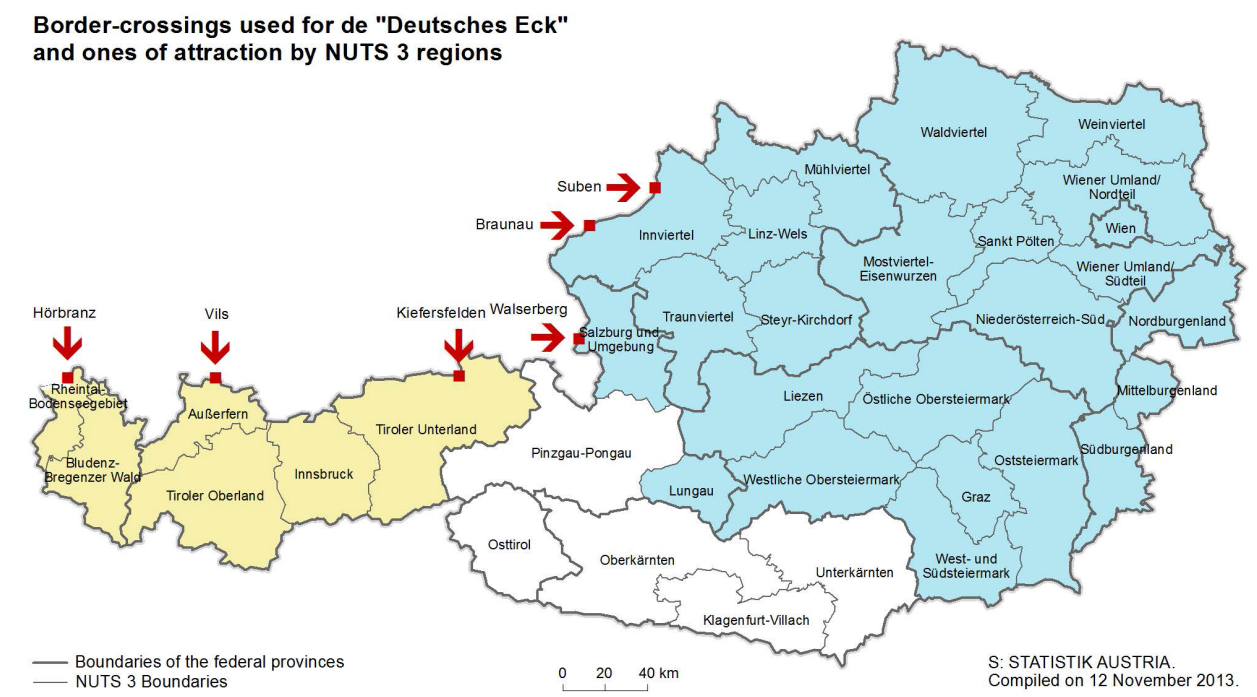

Figure 2: Border crossings "Deutsches Eck".

Example: trip from Innsbruck (NUTS 3 region AT332) to Vienna (NUTS 3 region AT130) The fastest route runs through the border crossings Kiefersfelden and Walserberg. First, the distance from the representative coordinates of AT332 (LAT 47.26; LON 11.39) to the coordinates of the border crossing Kiefersfelden (LAT 47.61; LON 12.19) was calculated by Microsoft MapPoint 2011. The same was done with the distance from the representative coordinates of AT130 (LAT 48.22; LON 16.38) to the coordinates of the border crossing Walserberg (LAT 47.77; LON 12.94). The results were $77.8 \mathrm{~km}$ and $307.0 \mathrm{~km}$ both driven in Austria, which amounted to 384.8 inland kilometres. For the foreign kilometres $94.0 \mathrm{~km}$ were derived between Kiefersfelden and Walserberg in Germany.

The kilometres calculated were then used to divide the total tonne-kilometres provided in table D3.1 into inland and foreign. In the example above, $80.37 \%$ of the 478.8 kilometres 
derived from Innsbruck to Vienna are inland and 19.63\% foreign. Assuming total tonnekilometres of 5,000 for this transportation, the estimated inland tonne-kilometres would be $4,018.5$.

\subsection{International Receipt and Dispatch}

International receipt and dispatch are characterised by having one NUTS 3 region in Austria and one abroad an Austrian border crossing. To estimate the inland transport performance, it was necessary to split the total transport performance by the percentage of the distance driven within Austria. Moreover, it had to be taken into account that multiple possible routes could have been taken. Consequently, it was important to define the most likely route between two NUTS regions, which was assumed to be the fastest route.

The border crossing is a crucial component in estimating the inland kilometres in international receipt and dispatch, as it marks the geographical point where the vehicle enters or leaves Austria. However, Austria has about 140 possible border crossings. As this would result in an impractically long computing time, the border crossings were reduced to those likely to be used frequently by road freight vehicles, which tended to be heavy and long. Also, in cases where there were highways and smaller roads both with border crossings close to each other, only the border crossings of the highways were considered. With this method, 21 border crossings were selected which are frequently used by road freight vehicles and which are distributed along the border in a way to leave no large stretches unattended (see Figure 3): Walserberg, Braunau, Suben, Wullowitz, Gmünd, Kleinhaugsdorf, Drasenhofen, Berg/Kittsee, Nickelsdorf, Klingenbach, Heiligenkreuz, Spielfeld, Rosenbach/Karawankentunnel, Arnoldstein, Sillian, Brennerpass, Feldkirch-Bangs, Lustenau, Hörbranz, Vils and Kiefersfelden.

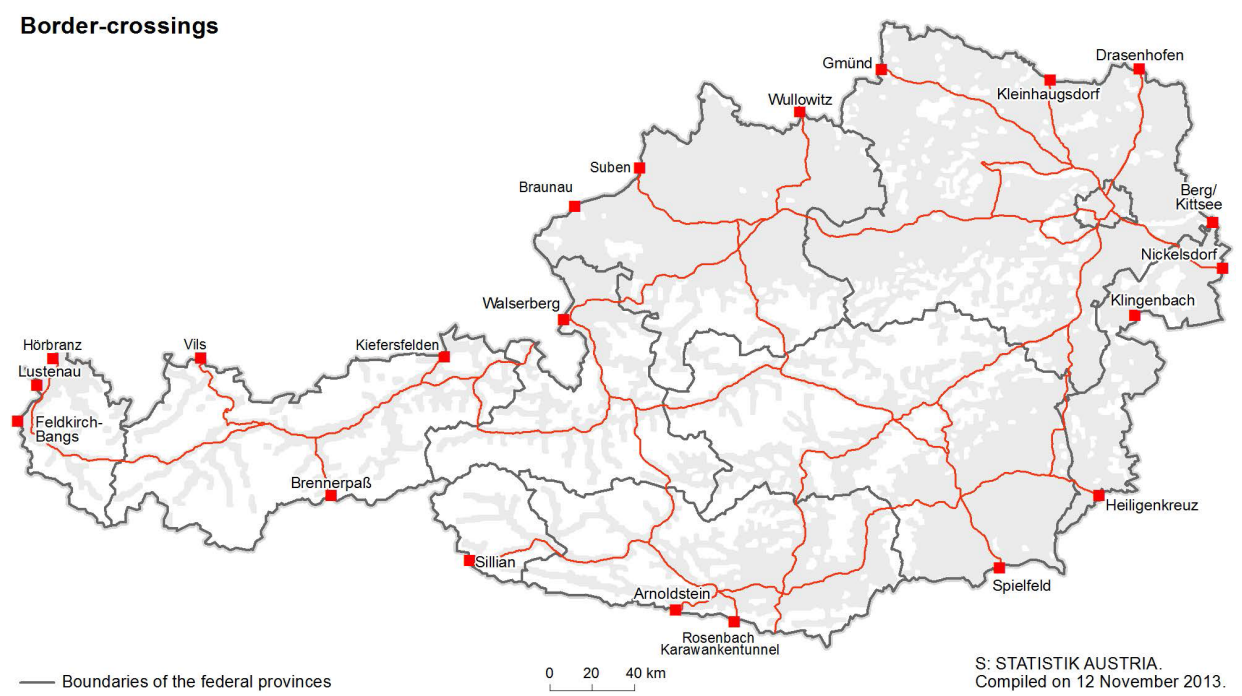

Figure 3: Border crossings.

As a next step a NUTS 3 matrix was created, which includes all possible combinations of the 35 Austrian NUTS 3 regions and the 1,259 foreign ones. For countries outside the EU involved in the road freight survey, which were not divided into NUTS regions, a representative coordinate was chosen and also linked to the 35 Austrian NUTS 3 regions.

Each of those combinations was joined with the 21 border crossings, hence 21 distance calculations were done in Microsoft MapPoint 2011 for each region combination. The kilometre results of the fastest route of each combination were then inserted into the matrix.

By using only the 21 border crossings, about 1.4 million routes had to be calculated. If all border crossing had been used, even the small ones, almost 7 million routes would have been computed, resulting in five times as much computing time.

Example: international dispatch from Vienna (AT130) to Torino in Italy (ITC11) 
To find the fastest route and the corresponding border crossing the 21 routes between those regions via the 21 border crossings were calculated and the resulting times were analysed. This procedure is depicted in Table 1 . The fastest way -9.05 hours was found to be via the border crossing Arnoldstein. The distance from Vienna to Arnoldstein, 394 kilometres, was saved as the inland distance for this NUTS 3 combination; the distance from Arnoldstein to Torino amounted to 620 kilometres and was inserted as the foreign distance.

Table 1: Transport routes via different boarder crossings calculated from Vienna (NUTS 3 AT130) to Torino (NUTS 3 ITC11) in 2012.

\begin{tabular}{l|cccccc} 
border crossing & inland km & foreign $\mathrm{km}$ & total km & inland time* & foreign time* & total time* $^{*}$ \\
\hline Walserberg & 307 & 699 & 1,006 & 3 & 6.45 & 9.45 \\
Braunau & 288 & 747 & 1,035 & 3.03 & 7.3 & 10.33 \\
Suben & 262 & 813 & 1,075 & 2.63 & 7.58 & 10.21 \\
Wullowitz & 199 & 895 & 1,094 & 2.52 & 8.47 & 10.99 \\
Gmünd & 139 & 936 & 1,075 & 1.72 & 9.1 & 10.82 \\
Kleinhaugsdorf & 75.6 & 1,075 & $1,150.6$ & 0.95 & 9.65 & 10.6 \\
Drasenhofen & 82.8 & 1,074 & $1,156.8$ & 1.05 & 9.6 & 10.65 \\
Berg/Kittsee & 70.3 & 1,067 & $1,137.3$ & 0.83 & 9.38 & 10.21 \\
Nickelsdorf & 74.6 & 1,028 & $1,102.6$ & 0.82 & 9.25 & 10.07 \\
Klingenbach & 67.3 & 980 & $1,047.3$ & 0.8 & 8.65 & 9.45 \\
Heiligenkreuz & 180 & 881 & 1,061 & 1.88 & 8 & 9.88 \\
Spielfeld & 240 & 779 & 1,019 & 2.17 & 6.92 & 9.09 \\
Rosenbach/ & & & & & 6.35 & 10.38 \\
Karawankentunnel & 402 & 654 & 1,056 & 4.03 & $\mathbf{5 . 4 8}$ & $\mathbf{9 . 0 5}$ \\
Arnoldstein & $\mathbf{3 9 4}$ & $\mathbf{6 2 0}$ & $\mathbf{1 , 0 1 4}$ & $\mathbf{3 . 5 7}$ & 5.45 & 10.4 \\
Sillian & 441 & 525 & 966 & 4.95 & 4.6 & 9.52 \\
Brennerpass & 510 & 495 & 1,005 & 4.92 & 4.03 & 10.32 \\
Feldkirch-Bangs & 638 & 396 & 1,034 & 6.28 & 4.12 & 10.25 \\
Lustenau & 637 & 414 & 1,051 & 6.13 & 4.4 & 10.28 \\
Hörbranz & 616 & 436 & 1,052 & 5.88 & 5.63 & 11.48 \\
Vils & 568 & 528 & 1,096 & 5.85 & 5.65 & 9.6 \\
Kiefersfelden & 405 & 609 & 1,014 & 3.95 & & \\
* time in hours in decimal notation & & & &
\end{tabular}

The NUTS 3 distance matrix was then used to derive the inland tonne-kilometres from the total tonne-kilometres. For each NUTS 3 combination the ratio of the inland kilometres to the total kilometres is the same as the ratio of the inland to the total transport performance. Therefore, the percentage of the inland distance was derived from the inland and foreign kilometres stored in the matrix and then applied to the total transport performance.

Example continued: Using the example above, the inland percentage of the distance in kilometres (394 inland kilometres of 1,014 total kilometres) was $38.86 \%$. Assuming a total transport performance of 5,000 tonne-kilometres, the inland transport performance would amount to 1,943 inland tonne-kilometres, based on the inland percentage.

\subsection{Transit Transport}

Data on transit transport through Austria is available in table D5. It gives information on the NUTS 3 regions of loading and unloading and the fact that the transportation passes through Austria, whereas information on the route the vehicle took is not provided. Moreover, the total transport performance is not included; hence the segmentation approach developed for national transport and international receipt and dispatch could not be used. Therefore, the kilometres driven within Austria were estimated using Microsoft MapPoint 2011 and then multiplied by the tonnes of each NUTS 3 combination given in table D5 to derive the inland transport performance. 
To estimate the inland kilometres of the fastest route between the representative coordinates of each pair of NUTS 3 regions, the border crossings used when driving this route had to be identified. As a result, a procedure to identify those border crossings was developed.

First, a list of all countries of loading or unloading was compiled. Then, for each country, Austrian border crossings were determined by expert knowledge, which would be taken on the fastest routes through Austria when entering/exiting Austria coming from/going to the respective country. They were selected from the list of the 21 border crossings which were already in use for international receipt and dispatch.

As an example, transports from Italy through Austria would have to enter the border crossings Arnoldstein, Sillian, Brennerpass, Feldkirch-Bangs or Lustenau. Also, if it was unloaded in Germany, the vehicle would most likely leave Austria through Braunau, Suben, Wullowitz, Walserberg, Vils, Kiefersfelden or Hörbranz. The list of countries with their possible border crossings is displayed in Table 2 .

Table 2: Probable border crossings by country in 2012 .

\begin{tabular}{|c|c|}
\hline Country code & Probable border crossings \\
\hline $\mathrm{AL}, \mathrm{BA}, \mathrm{BG}, \mathrm{ME}, \mathrm{MK}$, & \\
\hline TR, CY, GR, RO, RS & Nickelsdorf, Karawankentunnel, Spielfeld \\
\hline $\mathrm{AZ}$ & Nickelsdorf, Karawankentunnel \\
\hline $\mathrm{BE}, \mathrm{NL}, \mathrm{LU}$ & Braunau, Suben, Walserberg, Vils, Kiefersfelden, Hörbranz \\
\hline BY & Drasenhofen, Kiefersfelden \\
\hline $\mathrm{CH}, \mathrm{LI}$ & Feldkirch-Bangs, Lustenau \\
\hline $\mathrm{CZ}$ & $\begin{array}{l}\text { Gmünd, Kleinhaugsdorf, Drasenhofen, Braunau, } \\
\text { Suben, Wullowitz, Kiefersfelden, Hörbranz }\end{array}$ \\
\hline DE & Braunau, Suben, Wullowitz, Walserberg, Vils, Kiefersfelden, Hörbranz \\
\hline DK & Drasenhofen, Suben, Walserberg, Vils, Kiefersfelden, Hörbranz \\
\hline $\mathrm{EE}, \mathrm{LT}, \mathrm{LV}$ & Drasenhofen, Berg/Kittsee \\
\hline $\mathrm{FI}, \mathrm{NO}, \mathrm{SE}$ & Drasenhofen, Suben, Kiefersfelden, Hörbranz \\
\hline $\mathrm{FR}$ & $\begin{array}{l}\text { Arnoldstein, Braunau, Suben, Walserberg, Vils, Brennerpass, } \\
\text { Feldkirch-Bangs, Lustenau, Hörbranz }\end{array}$ \\
\hline HR & Nickelsdorf, Arnoldstein, Karawankentunnel, Spielfeld \\
\hline HU & Berg/Kittsee, Nickelsdorf, Klingenbach, Heiligenkreuz, Spielfeld \\
\hline IE & $\begin{array}{l}\text { Braunau, Suben, Walserberg, Vils, Kiefersfelden, Feldkirch-Bangs, } \\
\text { Lustenau, Hörbranz }\end{array}$ \\
\hline IT & Arnoldstein, Sillian, Brennerpass, Feldkirch-Bangs, Lustenau \\
\hline MD & Berg/Kittsee, Nickelsdorf, Klingenbach \\
\hline MT & Arnoldstein, Brennerpass, Feldkirch-Bangs, Lustenau \\
\hline PL & $\begin{array}{l}\text { Drasenhofen, Berg/Kittsee, Suben, Braunau, Walserberg, } \\
\text { Kiefersfelden, Hörbranz }\end{array}$ \\
\hline $\mathrm{ES}, \mathrm{PT}$ & Brennerpass, Feldkirch-Bangs, Lustenau \\
\hline RU & Drasenhofen, Nickelsdorf, Spielfeld, Kiefersfelden, Hörbranz \\
\hline SI & Karawankentunnel, Spielfeld \\
\hline SK & Berg/Kittsee \\
\hline UA & Drasenhofen, Nickelsdorf, Hörbranz \\
\hline UK & Suben, Walserberg, Kiefersfelden, Hörbranz \\
\hline
\end{tabular}

Then, for each NUTS 3 combination, the time needed for taking the fastest route through each combination of the possible border crossings from the list was calculated. Using this approach for about 28, 300 NUTS 3 to NUTS 3 combinations more than 782, 500 route calculations were done for transit transport for the years 2009 to 2012.

Example: transport from NUTS 3 Torino (ITC11) to NUTS 3 Böblingen (DE112)

For this journey $5 \times 7$ routes had to be calculated. Seven routes were generated from ITC11 to DE112, each running through the border crossing Arnoldstein and one of the seven German border crossings. This was done with the other four Italian border crossings as well, producing the 35 routes mentioned. 
Among the 35 possibilities, the fastest route was chosen and the two border crossings used were selected for this NUTS 3 combination. However, when using this approach on all NUTS 3 combinations, an unlikely high number of transports ran through the border crossings Hörbranz, Feldkirch or Lustenau. The national data for Austrian vehicles showed that they are rarely used if the transport did not start or end in either Switzerland or Liechtenstein. Consequently, these border crossings were allowed only in connection with regions of loading or unloading in Switzerland or Liechtenstein. Table 3 displays the results of this method for this example.

Table 3: Transport routes calculated from Torino (NUTS 3 ITC11) to Böblingen (NUTS 3 DE112) in 2012.

\begin{tabular}{llcccc}
$\begin{array}{l}\text { Italian border } \\
\text { crossing } \\
\text { (entry) }\end{array}$ & $\begin{array}{l}\text { German border } \\
\text { crossing } \\
\text { (exit) }\end{array}$ & $\begin{array}{c}\text { Time* from } \\
\text { ITC11 to Italian } \\
\text { border crossing }\end{array}$ & $\begin{array}{c}\text { Inland time* } \\
\text { between border } \\
\text { crossings }\end{array}$ & $\begin{array}{c}\text { Time* from } \\
\text { German border } \\
\text { crossing to DE112 }\end{array}$ & $\begin{array}{c}\text { Total } \\
\text { time* }\end{array}$ \\
\hline Arnoldstein & Wullowitz & 5.50 & 3.72 & 5.32 & 14.53 \\
& Suben & 5.50 & 3.32 & 3.77 & 12.58 \\
& Braunau & 5.50 & 2.80 & 3.38 & 11.68 \\
& Walserberg & 5.50 & 1.82 & 3.37 & 10.68 \\
Kiefersfelden & 5.50 & 2.77 & 2.98 & 11.25 \\
Sillian & Vils & 5.50 & 4.60 & 2.20 & 12.30 \\
& Wullowitz & 5.37 & 4.45 & 3.32 & 15.13 \\
& Suben & 5.37 & 4.07 & 3.77 & 13.20 \\
& Braunau & 5.37 & 3.53 & 3.37 & 12.28 \\
& Walserberg & 5.37 & 2.57 & 2.98 & 11.30 \\
& Kiefersfelden & 5.37 & 2.30 & 5.32 & 10.65 \\
Brennerpass & Vils & 5.37 & 3.22 & 3.77 & 14.78 \\
& Wullowitz & 4.58 & 4.23 & 3.38 & 12.00 \\
& Suben & 4.58 & 3.65 & 3.37 & 11.05 \\
& Braunau & 4.58 & 3.08 & 2.98 & 8.98 \\
& Walserberg & 4.58 & 2.38 & $\mathbf{2 . 2 0}$ & 8.87
\end{tabular}

Having determined the border crossings of entry to and exit from Austria on the fastest route for each combination of NUTS 3 regions, the inland kilometres had to be inserted. Those kilometres were taken from the distance matrix used to compile the national survey. Then these kilometres were multiplied by the tonnes given in table D5 for each combination of NUTS 3 regions to obtain the estimated inland transport performance.

Example continued: As this transport neither started nor ended in Switzerland or Liechtenstein, all routes going via the border crossings Hörbranz, Feldkirch or Lustenau were deleted. Of the 18 remaining tracks, the fastest one was chosen: Torino via Brennerpass and Vils to Böblingen within 8.87 hours. Then, the distance between Brennerpass and Vils was looked up in the distance matrix used in the national survey and inserted for this NUTS 3 combination. These 136.7 kilometres were then multiplied with the tonnage transported between these two NUTS 3 regions, resulting in the inland transport performance for this NUTS 3 combination.

\subsection{Problems with missing or incomplete regional data}

In both D-tables, problems arose from some observations in connection with the regional breakdown and, as a result, the abovementioned estimation methods could not be implemented automatically. One problem was that for either the point of loading or unloading, only the country level (NUTS 0 level) was included, even though this country is divided into NUTS 3 regions. To obtain a suitable coordinate for the route planner, it was therefore 
necessary to determine which NUTS 3 coordinate of this country was most appropriate.

In case of data lines based on single journeys with missing NUTS 3 regions in table D3.1, this was done by dividing the tonne-kilometres by the tonnes of that haulage to derive the total distance driven. Then, using the counterpart region, which was available on NUTS 3 level, and the distance driven, the most likely NUTS 3 region that could be reached was inserted.

Example: journey from Vienna (NUTS 3 AT130) to Croatia (NUTS 0 HR)

The distance driven (derived by dividing the total tonne-kilometres by tonnes) amounted to 775 kilometres. In inserting this data into Microsoft MapPoint 2011, the region "SplitDalmacia" (NUTS 3 HR035) was assumed to be the most likely NUTS 3 region of unloading. Very few data lines included more than one observation where the region of loading or unloading was only on NUTS 0 level. In those cases, this method was not applicable because the total distance could not be derived for each observation separately due to the fact that the total tonne-kilometres and tonnes were available only in aggregated form for all observations included in this data line. Therefore, the NUTS 3 region of the capital of the country was inserted as an approximation.

Also in table D5 on transit transport, observations were found where only either the point of loading or unloading was included on NUTS 3 level while the other was at country level (NUTS 0). However, the total distance driven could not be computed as the total tonnekilometres are not available in table D5. Hence, a different method had to be used for transit transport. For those observations, the country's most central NUTS 3 region was used as a proxy to determine suitable border crossings.

About two observations per year were found in table D5 where either the point of loading or unloading was completely omitted. In these cases no representative coordinates could be used at all; hence, no border crossings were defined and no inland kilometres could be inserted automatically. Therefore, as an approximation, the average of all possible inland transit distances through Austria was inserted to calculate the inland transport performance for these insular observations.

\section{Estimation results}

To prove the accuracy and quality of the approach, it was necessary to analyse from the D-tables how successful the estimation was and how valid the results were for the inland transport performance. For that purpose, the data from the national survey, where detailed information on the inland transport performance is available, was compared to the estimates received from the D-tables to check if they give approximately equivalent results. In the national survey, only vehicles registered in Austria are included; hence the results from the D-tables were restricted to those vehicles as well to attain a more comparable basis for the analysis.

Table 4 gives an overview of the results for national transport, international receipt and dispatch, and transit transport. The data on tonnes and total tonne-kilometres should be the same when comparing the national survey to the D-tables, but though Eurostat receives its data from the national surveys, they differ slightly. This is due to rounding differences arising because for the national survey the data is computed on a kilogram level, whereas Eurostat uses 100 kilograms as the basis before aggregating to tonne level. As the inland and foreign tonne-kilometres are calculated from the total tonne-kilometres, part of the divergence between the national survey and the D-table estimates will be due to this deviation in the total tonne-kilometres. To illustrate the magnitude of the rounding errors and the possible differences that could arise in the inland and foreign transport performance estimates, the tonnes and total tonne-kilometres are included in Table 4.

Keeping this in mind and looking more closely at the results in table 4, the estimates for national transport are found to be those with the highest percentage deviation from the national 
survey's data. Since the figures of total tonne-kilometres from the D-tables are $3.10 \%$ lower than in the national survey, the divergence of $3.77 \%$ in inland tonne-kilometres is negligible, since part of it may be due to rounding differences. With respect to foreign transport performance, a deviation of $12.04 \%$ is given. Considering the quantitative insignificance of the foreign transport performance in national transport (rd. 4.3\%), these results can be accepted.

For international receipt and dispatch the figures look even better. With differences of $-0.93 \%$ and $+0.25 \%$ in inland tonne-kilometres and of $-1.09 \%$ and $-1.92 \%$ in foreign tonnekilometres, the results of the estimation lie in very close proximity to the original results of the national survey.

For transit transport, both the foreign transport performance and also the total transport performance were not available. However, the estimated inland transport performance is only $1.33 \%$ below the results from the national survey. Since Austrian vehicles carried only 3.5\% of the total transport volume in transit transport in 2012, the sample for the analysis is rather small.

Therefore, the results of this analysis suggest that the approach was successful. Thus, the estimates of the inland transport performance from the D-tables for foreign European vehicles can be used to complete the national statistics.

Table 4: Transport volume and performance of Austrian vehicles from the national survey and the D-tables in 2012.

\begin{tabular}{|c|c|c|c|c|}
\hline & Tonnes & $\begin{array}{l}\text { Inland tonne- } \\
\text { kilometres in } 1,000\end{array}$ & $\begin{array}{l}\text { Foreign tonne- } \\
\text { kilometres in } 1,000\end{array}$ & $\begin{array}{l}\text { Total tonne- } \\
\text { kilometres in } 1,000\end{array}$ \\
\hline & \multicolumn{4}{|c|}{ National transport } \\
\hline National survey & $305,347,409$ & $13,509,779$ & $(603,854)$ & $14,113,633$ \\
\hline D-tables & $305,384,012$ & $13,000,105$ & 676,533 & $13,676,638$ \\
\hline \multirow[t]{2}{*}{ Difference in \% } & 0.01 & -3.77 & 12.04 & -3.10 \\
\hline & \multicolumn{4}{|c|}{ International receipt } \\
\hline National survey & $11,273,717$ & $1,193,842$ & $3,363,699$ & $4,557,541$ \\
\hline D-tables & $11,279,409$ & $1,182,695$ & $3,327,113$ & $4,509,808$ \\
\hline \multirow[t]{2}{*}{ Difference in \% } & 0.05 & -0.93 & -1.09 & -1.05 \\
\hline & \multicolumn{4}{|c|}{ International dispatch } \\
\hline National survey & $11,793,322$ & $1,248,463$ & $3,577,494$ & $4,825,957$ \\
\hline D-tables & $11,811,927$ & $1,251,626$ & $3,508,634$ & $4,760,261$ \\
\hline \multirow[t]{2}{*}{ Difference in $\%$} & 0.16 & 0.25 & -1.92 & -1.36 \\
\hline & \multicolumn{4}{|c|}{ Transit transport } \\
\hline National survey & $1,567,773$ & 190,524 & $\mathrm{n} / \mathrm{a}$ & $\mathrm{n} / \mathrm{a}$ \\
\hline D-tables & $1,564,021$ & 187,994 & $\mathrm{n} / \mathrm{a}$ & $\mathrm{n} / \mathrm{a}$ \\
\hline Difference in \% & -0.24 & -1.33 & $\mathrm{n} / \mathrm{a}$ & $\mathrm{n} / \mathrm{a}$ \\
\hline
\end{tabular}

Bold numbers are estimates from the approach.

Hence, the results for the inland transport performance of foreign vehicles from the D-tables were evaluated (see Table 5). According to the estimates from the D-tables, foreign vehicles performed 0.6 billion inland tonne-kilometres in national transport, 3.8 and 3.5 billion in international receipt and dispatch and 10.2 billion inland tonne-kilometres in transit transport. 
Table 5: Transport volume and performance of foreign vehicles from the D-tables in 2012.

\begin{tabular}{lcccc}
$\begin{array}{l}\text { Type of } \\
\text { transport }\end{array}$ & Tonnes & $\begin{array}{c}\text { Inland tonne- } \\
\text { kilometres in 1,000 }\end{array}$ & $\begin{array}{c}\text { Foreign tonne- } \\
\text { kilometres in 1,000 }\end{array}$ & $\begin{array}{c}\text { Total tonne- } \\
\text { kilometres in } 1,000\end{array}$ \\
\hline National transport & $3,663,646$ & $\mathbf{6 3 7 , 6 0 6}$ & $\mathbf{6 9 , 2 6 5}$ & 706,870 \\
International receipt & $28,186,082$ & $\mathbf{3 , 7 8 5 , 8 2 8}$ & $\mathbf{1 0 , 2 4 0 , 0 5 6}$ & $14,025,883$ \\
International dispatch & $24,050,978$ & $\mathbf{3 , 5 3 3 , 5 2 6}$ & $\mathbf{9 , 8 0 8 , 7 0 2}$ & $13,342,230$ \\
Transit transport & $42,562,172$ & $\mathbf{1 0 , 2 1 6 , 0 7 9}$ & $\mathrm{n} / \mathrm{a}$ & $\mathrm{n} / \mathrm{a}$ \\
\hline
\end{tabular}

Bold numbers are estimates from the approach.

\section{Discussion}

Referring to the approach described in this article there are further points for discussion left: For the approach the fastest route between the regions was chosen. Nevertheless, the route actually taken may be longer if there are roadblocks or temporary truck bans of any kind or if the driver wanted to minimize road charges and toll payments. In cases where the driver really chose the shortest route and the shortest route did not equal the fastest one, too many kilometres would have been calculated. These observations are assumed to be exceptions. Due to the opposed effects on the results, the bias should be minimal.

Concerning the representative geo-coordinates, the coordinate with the highest population density in the respective areas was chosen. It could be argued that for road freight transport this might not be an optimal choice; industrial areas should have been preferred. This is a valid argument and could be part of future research because geo-coordinates in regard to population density and to industrial compounds both have their eligibility. In fact, detailed information about industrial areas and their geo-coordinates is hardly available for all relevant countries.

Referring to the transport performance of foreign road freight vehicles, the approach is based on many assumptions. Using additional information like the number of foreign road freight vehicles registered by the several counting points of the toll data system would help to improve the estimation. Nevertheless, toll system data also has limits. For example, there is no difference between laden and empty journeys. Furthermore, data does not include exact information about the total weight of the single road freight vehicles or compulsory breaks of the truck drivers.

Finally, it has to be taken into account that road networks are dynamic. Over time, new roads are built and existing routes may be upgraded. Therefore, it is necessary to update the model in defined time intervals.

Related methods have also been developed by Eurostat and by the Kraftfahrt-Bundesamt in Germany and should be mentioned here:

Eurostat provides an Index for Locations for Statistics in Europe in the internet, the so-called WebILSE. Among other information, this tool comprehends the distances between all NUTS 3 regions in Europe and the inland parts for the involved countries. On this basis, the complete inland transport performance for each member state can be calculated for the road freight survey (Eurostat 2010).

Comparing the kilometre distances from WebILSE with the distances calculated in the Austrian model, first results showed a slight overestimation for receipt and dispatch and a slight underestimation for transit by WebILSE. One reason may be that different representative geo-coordinates were used in the route planner for the NUTS 3 regions. By further analysing the differences between the distances of the ILSE tool and the Austrian approach, it was detected, that many transit transportations through Austria are run through Switzerland (e.g. routes near the Bodensee) in the ILSE tool, thus creating only very few kilometres on Austrian territory. However, in the Austrian model, the routing was changed through Kiefersfelden 
and the Brennerpass, as many drivers probably avoid having to pay the road charges when driving through Switzerland, thus creating many more inland kilometres. This hypothesis is supported by the data from the Austrian road freight survey, where the drivers fill in the exact border crossings they used when driving through Austria. For the future additional analyses concerning both models are necessary.

Germany worked on a similar approach: the results can be found in Kraftfahrt-Bundesamt (2013). However, details referring to the methods could not yet be obtained.

\section{Conclusion}

This article describes a method developed to estimate the inland transport performance on Austrian territory performed by European road freight vehicles not registered in Austria. The data used was obtained from the consolidated European road freight statistics compiled by Eurostat (so-called "D-tables"). To assess the success of the procedure data from the Austrian road freight survey on the inland transport performance of Austrian road freight vehicles published by Statistics Austria was used.

As a first step, representative geo-coordinates for all regions included in the D-tables were determined using population density information. Secondly, those coordinates were used to locate the most likely routes taken in order to identify the inland part of the total transport performance coming from the D-tables. These steps were conducted for national transport, international receipt and dispatch. In addition, for transit transport a slightly different approach had to be used due to the fact that the total transport performance is not available in the D-tables. Hence the inland kilometres were estimated and then multiplied by the tonnage in order to obtain the inland transport performance.

Analysing the estimation results and the actual statistics of Austrian road freight vehicles, it was concluded that the method used is suitable for this purpose. Therefore, first solid estimates of the inland transport performance of foreign European road freight vehicles are available for Austria and were presented in this article. A critical discussion discovered some possibilities for further research to improve the model described.

\section{References}

Eurostat (2010). "Sectoral and regional statistics: Draft Report. Support for regional coding. Distance calculations methodology." Doc. Ref.: PN5C/05/2010/E4. Doc id: C10953B/BD/bd/005. URL http://epp.eurostat.ec.europa.eu/WebILSE.

Kraftfahrt-Bundesamt (2013). "Verkehr europäischer Lastkraftfahrzeuge (VE). Grenzüberschreitender Verkehr. Jahr 2011. VE 2." pp. 49-50. 


\author{
Affiliation: \\ Thomas Karner, Brigitte Weninger, Sylvia Scharl \\ Statistics Austria \\ Guglgasse 13 \\ A-1110 Vienna, Austria \\ E-mail: thomas.karner@statistik.gv.at \\ E-mail: brigitte.weninger@statistik.gv.at \\ E-mail: sylvia.scharl@statistik.gv.at \\ URL: http://www.statistik.at
}

\section{Austrian Journal of Statistics}

published by the Austrian Society of Statistics

Volume 43

April 2014 http://www .ajs.or.at/

http://www.osg.or.at/

Submitted: 2013-12-11

Accepted: 2014-03-25 